\title{
Efficacy and Safety of an Advanced Formula Silicone Gel for Prevention of Post-Operative Scars
}

\author{
Bikash Medhi • Rakesh Kumar Sewal • \\ Lileswar Kaman · Ganesh Kadhe · Amey Mane
}

To view enhanced content go to www.dermtherapy-open.com Received: July 6, 2013 / Published online: November 20, 2013

(C) The Author(s) 2013. This article is published with open access at Springerlink.com

\section{ABSTRACT}

Introduction: Scar formation is a natural part of the healing process that occurs when the skin repairs wounds caused by burns, trauma,

Electronic supplementary material The online version of this article (doi:10.1007/s13555-013-0036-8) contains supplementary material, which is available to authorized users.

B. Medhi $(\bowtie)$

Department of Pharmacology, Postgraduate Institute of Medical Education and Research (PGIMER), Chandigarh, India

e-mail: drbikashus@yahoo.com

R. K. Sewal

Department of Pharmacology, PGIMER,

Chandigarh, India

\section{Kaman}

Department of General Surgery, PGIMER,

Chandigarh, India

G. Kadhe · A. Mane

Medical Affairs Department, Wockhardt Ltd.,

Wockhardt Towers, Bandra (East), Mumbai, India

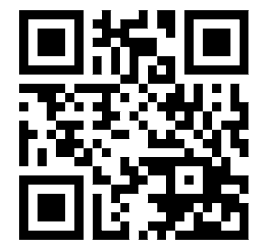

Enhanced content for this article is available on the journal web site:

www.dermtherapy-open.com surgery or disease. The appearance of scars often leads to adverse psychological effects, loss of self-esteem and the associated stigmatism and diminished quality of life. Silicones are emerging as the standard treatment for prevention of a wide range of scars. The present study evaluated the safety and efficacy of an advanced formula topical silicone gel for prevention of post-operative hypertrophic and keloid scars.

Methods: An open-label prospective trial was conducted. Patients who had undergone prior surgery (10 days-3 weeks) and having recent post-surgical scars were enrolled. Patients were asked to apply the gel twice daily to the affected areas for 3 months. Pigmentation, vascularity, pliability, height of scar and pain and pruritus in the scar were assessed. Photographs of scars were taken before commencement of treatment and at follow-up visits.

Results: A total of 36 patients were enrolled. At baseline, height of the scar was $2-5 \mathrm{~mm}$ in 57.6 $\%(19 / 33)$ of the subjects which was reduced in subsequent visits $(P<0.05)$. Hyperpigmentation (score 3) was present in 91\% (30/33) of patients at baseline and was reduced to normal (score 0 ) after 2 months of treatment 
in $40 \%(6 / 14)$ of patients $(P=0.0313)$. Vascularity $(54.6 \%, 18 / 33)$ at baseline was also reduced over the 3 months period $(P=0.0313)$ A significant decrease $(30 \%$, $3 / 10)(P=0.0313)$ in pliability was seen after 3 months of treatment from the baseline (57.6\%, 19/33). Only two patients reported pruritus and pain at the baseline visit; one patient reported improvement after treatment. Itching was reported as an adverse drug reaction in two patients.

Conclusion: These preliminary findings suggest that advanced formula silicone gel is safe and effective in the prevention of hypertrophic and keloid scars; however, larger, controlled studies are warranted.

Keywords: Dermatology; Hypertrophic; Keloid; Post-operative scar; Silicone gel

\section{INTRODUCTION}

Scarring is considered as the price paid for evolutionary survival after wounding [1]. The appearance of scars sometimes has adverse aesthetic, psychological, and social impact that may be associated with diminished quality of life [2]. There are various treatment methods available for scars, including surgery, radiation therapy, steroid injections, pressure therapy, cryotherapy (treatment with liquid nitrogen), and laser therapy, but silicone therapy has been proved to have primary role in scar management [3, 4]. Silicone-based products are widely used in preventing abnormal signs and symptoms in hypertrophic and keloids scars [3].

Topical silicone gel is easy to apply and cosmetically acceptable [5]. Previous studies have shown it to be an effective treatment for the treatment of scars [6-8]. A Cochrane review of 15 trials involving 615 patients compared adhesive silicone gel sheet (SGS) with control; non-silicone gel sheeting; silicone gel plates with added Vitamin E; laser therapy; triamcinolone acetonide injection, and nonadhesive silicone gel sheeting. SGS was found to be a beneficial treatment option for scarring [9]. Self-drying silicone gel is a relatively recent treatment option for scars. The ease of use, costeffectiveness and non-invasive nature of silicone gels add to its benefit. The transparent nature and flexibility of the gel could also improve patient compliance [3]. Moreover, topical self-drying silicone gel is approved by Food and Drug Administration (FDA) and has been recognized to overcome the practical difficulties of topical SGS [10].

Hydration and occlusion are the principal mode of action of silicone gel or silicone oil [11, 12], but the precise mechanism of action of silicon gels in treatment of scars remains unknown. Some possible mechanisms have been suggested, including (1) an increase in the skin surface temperature that might lead to increased collagenase activity [13], (2) increased tissue hydration through occlusion of the stratum corneum that could lead to a reduction in angiogenesis and reduced capillary perfusion $[3,14]$ and (3) development of a negatively charged static electric field generated by friction between silicone gel and the skin surface that could lead to collagen realignment [15].

The purpose of the current study was to determine the safety and efficacy of a patented topical advanced formula silicone gel for the management and prevention of post-operative scars. 


\section{METHODS}

\section{Study Population}

Eligible patients were aged $>18$ years with a recent post-surgical scar (linear hypertrophic, widely spread hypertrophic, major keloid, minor keloid, atrophic, or new scars) exhibiting at least one of the following characteristics: vascularity (redness), elevation (height) above surrounding skin (or depression if atrophic), pliability (hardness) compared with normal skin, pruritus (itching or pain) and had undergone prior surgery (10 days-3 weeks) and having recent post-surgical scars were enrolled. Those with known hypersensitivity/allergy to any of the ingredients of the treatment, scars with an open wound component or using medications/cosmetics likely to interfere with study results were excluded from the study.

\section{Study Design and Procedure}

This open-label prospective study evaluated the safety and efficacy of an advanced formula silicone gel (Kelo-cote ${ }^{\circledR}$, a topical SGS in the form of an easily applicable gel, Wockhardt Limited, Mumbai) conducted at the Postgraduate Institute of Medical Education and Research, Chandigarh, India, after clearance from the Institutional Ethics Committee. This 12-month study consisted of two phases and seven visits: a treatment phase that lasted 3 months and included four monthly visits from baseline and a follow-up phase that included three visits at 3-month intervals. All procedures followed were in accordance with the ethical standards of the responsible committee on human experimentation (institutional and national) and with the Helsinki Declaration of 1975, as revised in 2000 and 2008. The 3-month treatment phase was based on available literature and international guidelines for scar management $[16,17]$. The manufacturer also recommends using Kelo-cote ${ }^{\circledR}$ for a period of at least 3 months, starting once the surgical incision or wound has healed [18]. Patients received the silicone gel as a treatment for the scar after providing written informed consent. The gel was to be applied twice daily to the affected areas as a very thin layer and allowed to dry. For maximum efficacy, patients were advised to ensure constant contact of the gel with the skin.

At baseline, parameters including type of surgery, time elapsed since surgery, morphological characteristics of scar, and location and grade of the scar were recorded for every patient. Pigmentation, vascularity, pliability, height of scar and pain and pruritus in scar were assessed at baseline and all subsequent visits, using a scoring scale as shown in Table 1.

The Vancouver Scar Scale score was recorded at baseline and at every subsequent visit during treatment and follow-up (at 1, 2, 3, 6, 9 and 12 months). The schedule of patient visits for follow-up is presented in Table 2. Video recordings and photographs of the scar were taken at baseline and at 3 months. Changes in the morphological features of the scar were assessed using a 4-point scale before and after the study period (Grade 1: flat, soft, normal scar; Grade 2 or mildly hypertrophic: slightly elevated, moderately hard, light to dark pink color; Grade 3 or hypertrophic: elevated within wound margin, hard, dark pink to red color; Grade 4 or keloid: very elevated, larger than wound margin, very hard, red to brown color).

At the end of the study period, the Dermatological Quality of life Index (DLQI) questionnaire was completed by patients. The "Quality of life" score was calculated by summing 
Table 1 Scoring Scale for assessment parameters

\begin{tabular}{lllllll}
\hline Parameter & Score & \multicolumn{1}{l}{} \\
\cline { 2 - 7 } & $\mathbf{0}$ & $\mathbf{1}$ & $\mathbf{2}$ & $\mathbf{3}$ & $\mathbf{4}$ & $\mathbf{5}$ \\
\hline Pigmentation & Normal & Hypopigmentation & Hyperpigmentation & - & - & - \\
Vascularity & Normal & Pink & Red & Purple & - & - \\
Pliability & Normal & Supple & Yielding & Firm & Banding & Contracture \\
Height & Normal & $>2 \mathrm{~mm}$ & $2-5 \mathrm{~mm}$ & $<5 \mathrm{~mm}$ & - & - \\
Pain & None & Occasional & Requires medication & - & - & - \\
Pruritus & None & Occasional & Requires medication & - & - & - \\
\hline
\end{tabular}

Table 2 Schedule of visits and number of patients at each visit

\begin{tabular}{lll}
\hline Visits & Month of visit & No. of patients \\
\hline 1 & 0 (Baseline) & 33 \\
2 & 1st month & 18 \\
3 & 2nd month & 15 \\
4 & 3rd month & 10 \\
5 & 6th month & 7 \\
6 & 9th month & 1 \\
7 & 12th month & 0 \\
\hline
\end{tabular}

the score of questions. The higher the score, the more quality of life is impaired. Investigator and the patients also assessed the overall efficacy of the gel using a 4-point scale (1-complete satisfaction, 2-satisfied, 3-not completely satisfied, 4-not satisfied at all). Adverse events (AE) were monitored throughout the trial. At each scheduled visit, a safety assessment was conducted by the investigator. The intensity (mild/moderate/severe), relationship with the study drug (unrelated/possibly related/probably related/definitely related) and outcome (resolved/ persisted) were noted for all AEs. If the patient dropped out of the study, the possible reasons for drop-out, including no improvement in the scar, or occurrence of unacceptable signs/symptoms, were also documented.

\section{Statistical Analysis}

Descriptive statistics were used for demographic data. Mean scores for height, vascularity, pigmentation and pliability were analyzed and Wilcoxon signed rank test used to compare values between baseline and subsequent visits. A $P$ value of less than 0.05 was considered as statistically significant. Statistical analysis was performed using SPSS software package (IBM SPSS software, USA http://www-01.ibm.com/ software/analytics/spss/).

\section{RESULTS}

\section{Patients}

A total of 36 patients [male 13; female 23 (63.9\%)] participated in the study. The mean age $(n=36)$ was $35.7 \pm 13.9$ years, mean height $(n=18) 1.6 \pm 0.07 \mathrm{~m}$ and mean weight $(n=17)$ $60.1 \pm 13.6 \mathrm{~kg}$. The location and type of scar are presented in Table 3. In most patients, the scar was located in the abdominal region (62.8\%). After recruitment of these 36 patients, it was observed that that the scars of three patients did not meet the inclusion criteria. Thus, only 33 patients were included in the analysis. Most of the scars were Grade 3 (61.3\%, 19/31), followed by Grade $2(19.4 \%, 6 / 31)$ and Grades 1 and 4 
Table 3 Scar Location and Type

\begin{tabular}{llc}
\hline Scar location & Scar type & $\begin{array}{l}\text { No. of } \\
\text { patients (\%) }\end{array}$ \\
\hline Abdomen & Linear hypertrophic & $16(45.7)$ \\
& Widely spread hypertrophic & $1(2.9)$ \\
& Not given & $5(14.3)$ \\
Arm & Linear hypertrophic & $2(5.7)$ \\
& Minor keloid & $2(5.7)$ \\
& Not given & $2(5.7)$ \\
Face & Linear hypertrophic & $1(2.9)$ \\
& Not given & $1(2.9)$ \\
Foot & Atrophic & $1(2.9)$ \\
Neck & Linear hypertrophic & $1(2.9)$ \\
Nose & Not given & $1(2.9)$ \\
Shoulder & Minor keloid & $2(5.7)$ \\
Total & & $35(100)$ \\
\hline
\end{tabular}

(9.7\% 3/31 each). The number of patients for follow-up at every visit is presented in Table 2 . No patients were available for follow-up after 9 months.

\section{Efficacy Assessment}

At baseline, the most common score for height and measurement of scars was 2 ( 2 to $5 \mathrm{~mm}$ ) (57.6\%, 19/33). There was a significant reduction in the height and measurement scores from baseline to the end of first month and subsequent months of visit $(P<0.05)$ for scars of all heights and measurements. Scores for height, pigmentation, pliability, and vascularity are presented in Table 4 . The pliability score of the majority of scars was 3 (firm) at baseline in $57.6 \%(19 / 33)$ of subjects, and this was reduced significantly at the first (5/18), second (5/14) and third (3/10) months of treatment $(P<0.05)$. The difference in measurement of vascularity of the scars from baseline was significant after 3 months of treatment $(P<0.05)$. None of the patients reported pain in the scar at baseline and subsequent visits. About 91\% (30/33) of the scars $(n=30)$ had hyperpigmentation (score 2$)$ at baseline that reduced significantly at the end of 2 months $(P<0.05)$. Overall, significant reduction in all scar parameters was observed with the use of advanced formula silicone gel. Before and after treatment, images of scars of some of the patients are shown in Figs. 1, 2, 3, and 4.

Table 5 presents the DLQI assessment scores during the study period. There is a significant difference between baseline measurements of Quality of life scores when compared with 3-month measurements $(P<0$.0313).

Overall, after 3 months of using the gel, the investigator was completely satisfied with the healing of the scar in $71.4 \%(n=10)$ of cases, while $30.7 \% \quad(n=4)$ of the patients were completely satisfied. Only two patients reported pruritus and pain at the baseline visit: one patient reported an improvement whereas the other did not. Only two patients reported itching as an adverse effect after application of the gel.

\section{DISCUSSION}

The results of the present study show a beneficial efficacy and safety profile of advanced formula silicone gel (Kelo-cote ${ }^{\circledR}$ ). Scar height, pain, pigmentation, pliability, pruritus and vascularity of the scars showed a significant improvement from baseline and there was a significant reduction in the Vancouver scar scale from baseline. The DLQI assessment score also showed a significant improvement from baseline. 
Table 4 Scar height, pigmentation, vascularity and pliability at baseline, visit 3 (after 2 months) and visit 4 (after 3 months)

\begin{tabular}{|c|c|c|c|c|c|c|}
\hline \multirow[t]{2}{*}{$\operatorname{Parameter}(n)$} & \multicolumn{5}{|c|}{ Score, $n(\%)$} & \multirow[t]{2}{*}{$P$ value } \\
\hline & $\overline{0}$ & 1 & 2 & 3 & 4 & \\
\hline \multicolumn{7}{|l|}{ Height } \\
\hline Baseline (33) & $3(9.1 \%)$ & $9(27.3 \%)$ & $19(57.6 \%)$ & $2(6.1 \%)$ & - & - \\
\hline Visit 3 (14) & $3(20 \%)$ & $8(53.3 \%)$ & $3(20 \%)$ & 0 & - & $0.0020^{*}$ \\
\hline Visit 4 (10) & $5(50 \%)$ & $4(40 \%)$ & $1(10 \%)$ & 0 & & $0.0156^{*}$ \\
\hline \multicolumn{7}{|l|}{ Pigmentation } \\
\hline Baseline (33) & $2(6.1 \%)$ & $1(3.03 \%)$ & $30(90.9 \%)$ & - & - & - \\
\hline Visit 3 (14) & $6(40 \%)$ & 0 & $8(55.3 \%)$ & - & - & $0.0313^{*}$ \\
\hline Visit 4 (10) & $5(50 \%)$ & 0 & $5(50 \%)$ & & & 0.0625 \\
\hline \multicolumn{7}{|l|}{ Pliability } \\
\hline Baseline (33) & $3(9.1 \%)$ & $3(9.1 \%)$ & $3(9.1 \%)$ & $19(57.6 \%)$ & $5(15.1 \%)$ & - \\
\hline Visit 3 (14) & $2(14.3 \%)$ & $3(21.4 \%)$ & $4(28.6 \%)$ & $5(35.7 \%)$ & 0 & $0.0039^{*}$ \\
\hline Visit 4 (10) & $6(60 \%)$ & $1(10 \%)$ & 0 & $3(30 \%)$ & 0 & $0.0313^{*}$ \\
\hline \multicolumn{7}{|l|}{ Vascularity } \\
\hline Baseline (33) & $4(12.1 \%)$ & $2(6.1 \%)$ & $18(54.6 \%)$ & $9(27.3 \%)$ & - & - \\
\hline Visit 3 (14) & $5(35.7 \%)$ & $3(21.4 \%)$ & $2(14.3 \%)$ & $42(8.6 \%)$ & - & $0.0195^{*}$ \\
\hline Visit 4 (10) & $4(50 \%)$ & $1(10 \%)$ & $1(10 \%)$ & $3(30 \%)$ & & 0.0313 \\
\hline
\end{tabular}

$n$ number of subjects

${ }^{*}$ Statistically significant difference from baseline at visit 3 and visit $4(P$ value $<0.05)$ for all parameters (except pigmentation at visit 4). $P$ value compared mean score after 3 months versus baseline

Scar management is challenging with many treatment options available, but none is proven to be effective. Topical application of SGS and intralesional injection of corticosteroids are the first-line treatment options that have sufficient evidence for scar management but require strict adherence [3]. Cryosurgery or cryotherapy has shown promising results for smaller scars such as acne but may cause hypopigmentation and pain in some cases [19, 20]. Furthermore, sensitive patients are unable to tolerate the associated pain and discomfort and require anesthesia [21]. SGS has been frequently used as a noninvasive means to treat scars [17]. Adhesive and flexible SGS such as Cica-care have been found to be effective for scar management with easy use and patient acceptability $[22,23]$, but the requirement of a light elastic bandage or tape to hold the sheet in place [24] may limit the use of Cica-care. However, use of self-drying silicone gel is easier to apply with no fixation required. Moreover, it is invisible when dry; and sun blocks, makeup or both can be applied in combination. These factors might also lead to an increase in patient compliance, as reported in previous studies $[7,8]$.

The advanced formula silicone gel used in the present study is a topical SGS in the form of an easily applicable gel, for hypertrophic and 

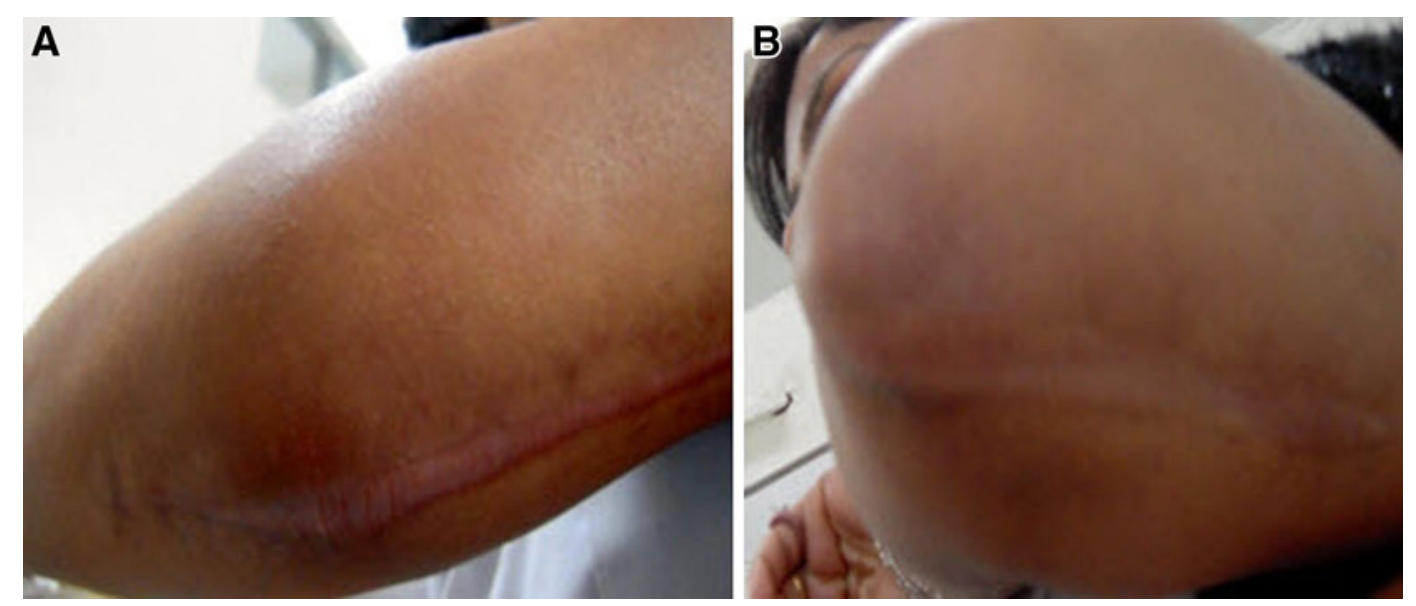

Fig. 1 a Scar on elbow before the silicone gel treatment. b View 7 months after silicone gel application
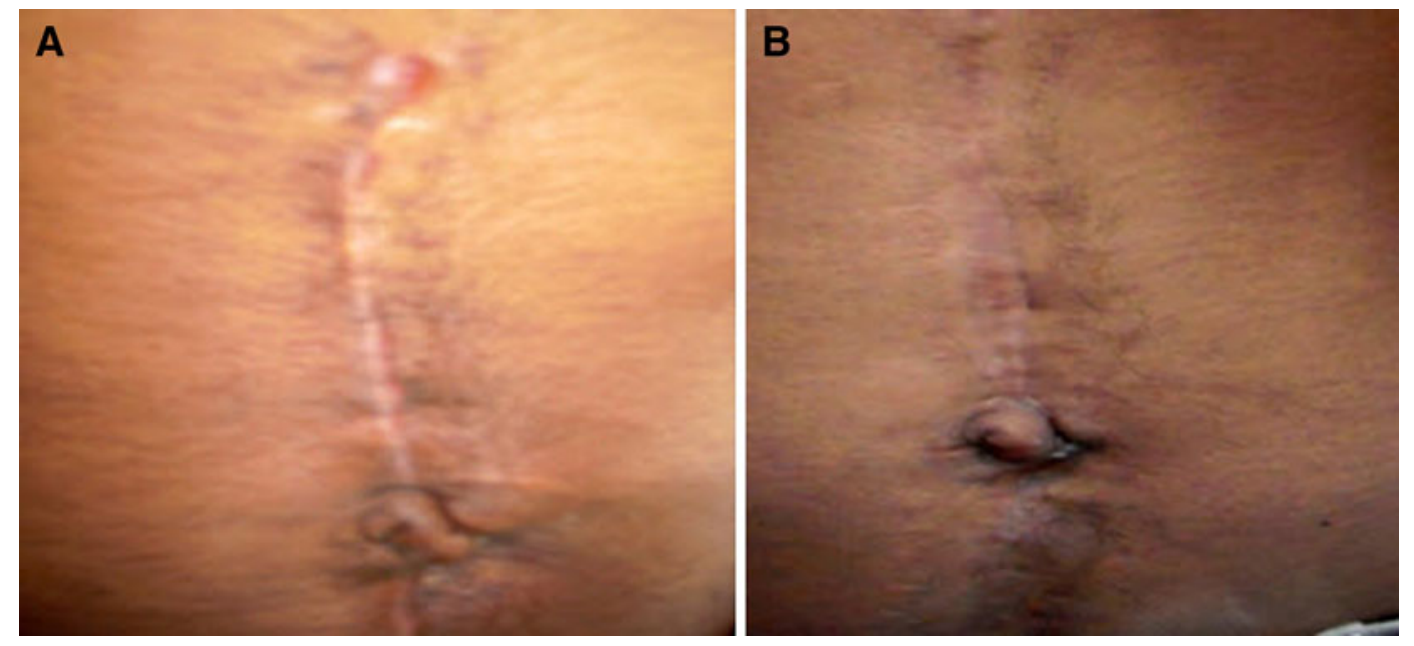

Fig. 2 a Scar on abdomen before the silicone gel treatment. b View 3 months after silicone gel application
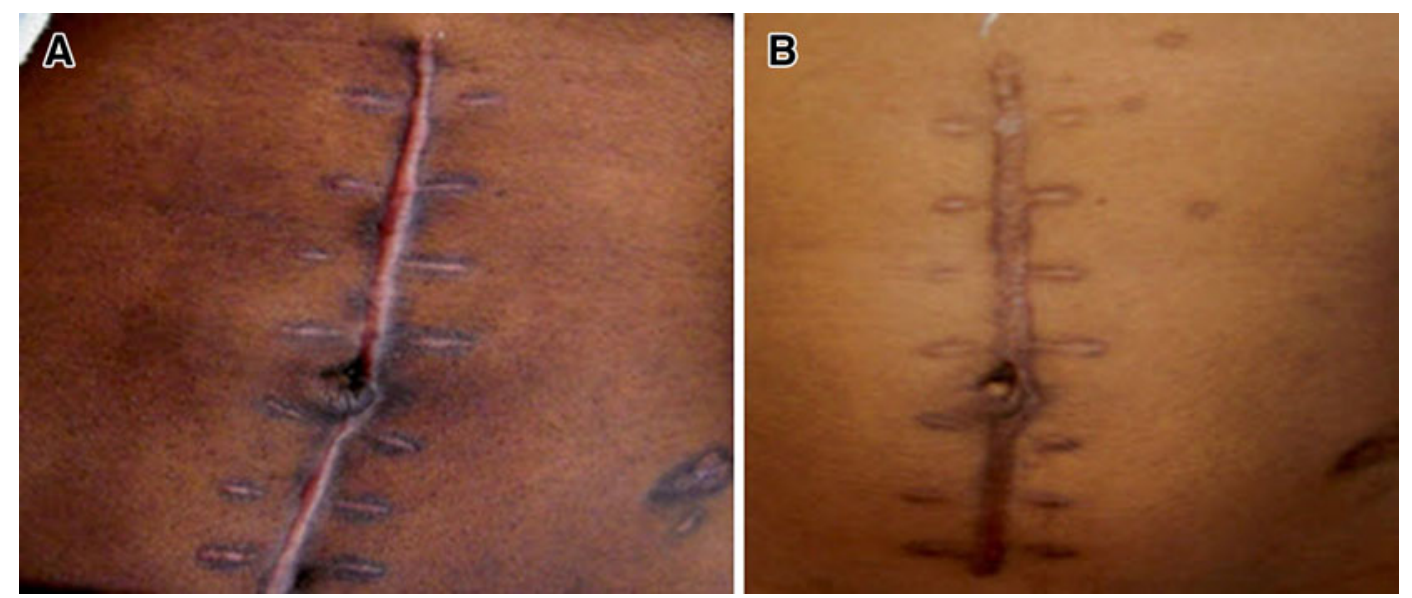

Fig. 3 a Scar on abdomen before the silicone gel treatment. b View 4.5 months after silicone gel application 

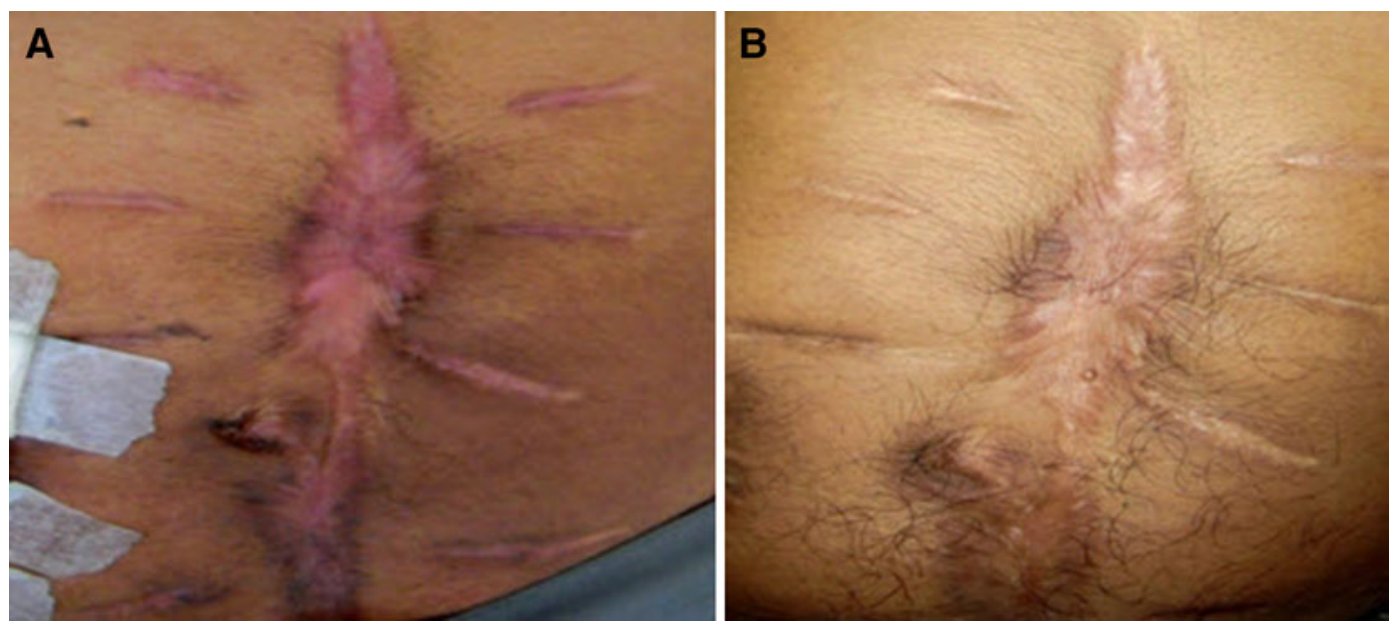

Fig. 4 a Scar on abdomen before the silicone gel treatment. b View 4.5 months after silicone gel application

Table 5 Dermatological Quality of Life Index Scores

\begin{tabular}{llll}
\hline Visit & No. of patients & Mean $(\mathrm{SD})$ & $\boldsymbol{P}$ value \\
\hline Baseline & 18 & $0.49(0.3)$ & - \\
3 months & 13 & $0.34(0.3)$ & 0.03 \\
6 months & 6 & $0.31(0.4)$ & - \\
9 months & 3 & $0.07(0.1)$ & - \\
\hline
\end{tabular}

$S D$ standard deviation

keloid scarring resulting from trauma, surgery, burns and other events. It is a class I medical device with a European CE mark and has been approved by the US FDA. The gel delivers a thin layer of the patented silicone formulation to the skin, which then cross-links and dries to form an ultrathin breathable and durable sheet on the skin.

In the present study, a significant reduction in pigmentation, pliability, vascularity, and height was observed at the end of 3 months. Previous studies with silicone gel have shown similar promising results with a significant reduction in hyperpigmentation [7, 8, 25-27]. Chan et al. in their study reported differences in response to silicone gel among 50 patients. Decrease in pigmentation was seen after 6 weeks of using silicone gel on hypertrophic scars. The mean scores of height, vascularity, pliability were reduced in the silicone gel group after 3 months, as compared to the control group [8]. Chittoria et al conducted a study comparing silicone gel with placebo in skin graft donors and found a significant reduction in overall scores and individual parameters of height, vascularity, pliability and pigmentation [7].

Pain, itching and burning sensation are common adverse events that have been observed with silicon gels. In the present study, only two patients reported itching as an adverse event after application of the advanced silicone gel. Only two patients reported pruritus and pain at the baseline visit, with one patient reporting an improvement at the subsequent visit. In a previous study by Sepehrmanesh et al. [27], about $99 \%$ of the patients and physicians rated the tolerability of silicone gel as either good or very good. Other studies did not observe any adverse events with the use of silicone gel [6-8].

Sepehrmenash et al. observed that in their study of 1,522 patients, physicians rated the improvement of the various scar symptoms as 
"good" or "very good" in 70-84\% of all cases and this evaluation was almost entirely consistent with that reported by the patients (69.8-85\%) [27]. In our study, the investigator was 'completely satisfied' or 'satisfied' in about 79\% of the cases, while approximately $54 \%$ of the patients were 'completely satisfied' or 'satisfied' with the healing of their scar in the present study. The difference in the ratings between physician and patients might be due to a small study size and loss of patients to follow-up. The appearance of scars can potentially lead to a diminished quality of life. In the present study, patients reported a significant improvement in the DLQI scores after 3 months $(P<0.0313)$.

Although silicone gel is safe, easy to apply and has good efficacy, some patients have complained about a prolonged drying time being required, but the problem can be overcome by using a hair dryer $[5,6,28]$. Moreover, silicone gel requires no fixation, and is invisible when dry and durable [5]. As SGS is safe and non-invasive, it can be used for both prevention and treatment [13]. Foo et al. [29] reported that there was no single universally accepted treatment that can eliminate hypertrophic scars; however, SGS remains the most accepted modality for treatment and prevention of scars.

In the present study, advanced silicone gel has shown promising results in scar management; however, there were some limitations in our study, including a small number of patients and short duration of follow-up. At the end of 9 months, only one patient could be examined and there were no follow-up data after this timepoint. Furthermore, investigator and patients were not blinded to the treatment received and there was no control group. Considering all these factors, the results of this study should be considered as preliminary.

\section{Conclusions}

In conclusion, advanced silicone gel appears to be a safe and effective treatment for management of scars. We recommend further randomized studies that are adequately powered to gather more data.

\section{ACKNOWLEDGMENTS}

Sponsorship and article processing charges for this study was funded by Wockhardt Ltd. Kelo-cote ${ }^{\circledR}$ is being marketed by Wockhardt Ltd. in India in collaboration with Sinclair pharmaceutical Ltd. Dr. Medhi is the guarantor for this article, and takes responsibility for the integrity of the work as a whole. The authors acknowledge Ms. Geetika Kainthla, Medical Writer, Knowledge Isotopes Pvt. Ltd. (http://www.knowledgeisotopes.com) for the writing support, Wockhardt Ltd funded this support.

Conflict of interest. Dr. Medhi, Dr. Sewal and Dr. Kaman declare no conflict of interest. Dr. Mane is an employee of the Wockhardt Ltd. Dr. Khade is an employee of the Wockhardt.

Compliance with ethics guidelines. All procedures followed were in accordance with the ethical standards of the responsible committee on human experimentation (institutional and national) and with the Helsinki Declaration of 1975, as revised in 2000 and 2008.

Open Access. This article is distributed under the terms of the Creative Commons Attribution Noncommercial License which permits any noncommercial use, distribution, and reproduction in any medium, provided the original author(s) and the source are credited. 


\section{REFERENCES}

1. Bayat A, McGrouther DA, Ferguson MW. Skin scarring. BMJ. 2003;326:88-92.

2. Bock O, Schmid-Ott G, Malewski P, Mrowietz U. Quality of life of patients with keloid and hypertrophic scarring. Arch Dermatol Res. 2006;297:433-8.

3. Mustoe TA. Evolution of silicone therapy and mechanism of action in scar management. Aesthetic Plast Surg. 2008;32:82-92.

4. Berman B, Perez OA, Konda S, et al. A review of the biologic effects, clinical efficacy, and safety of silicone elastomer sheeting for hypertrophic and keloid scar treatment and management. Dermatol Surg. 2007;33:1291-303.

5. Puri N, Talwar A. The efficacy of silicone gel for the treatment of hypertrophic scars and keloids. J Cutan Aesthet Surg. 2009;2:104-6.

6. Signorini M, Clementoni MT. Clinical evaluation of a new self-drying silicone gel in the treatment of scars: a preliminary report. Aesthetic Plast Surg. 2007;31:183-7.

7. Chittoria RK, Padi TR. A prospective, randomized, placebo controlled, double blind study of silicone gel in prevention of hypertrophic scar at donar site of skin grafting. J Cutan Aesthet Surg. 2013;6:12-6.

8. Chan KY, Lau CL, Adeeb SM, Somasundaram S, Nasir-Zahari M. A randomized, placebo-controlled, double-blind, prospective clinical trial of silicone gel in prevention of hypertrophic scar development in median sternotomy wound. Plast Reconstr Surg. 2005;116:1013-20 discussion 1021-2.

9. O'Brien L, Pandit A. Silicon gel sheeting for preventing and treating hypertrophic and keloid scars. Cochrane Database Syst Rev. 2006;1: CD003826.

10. FDA. Premarket Notification Database. http://www. accessdata.fda.gov/cdrh_docs/pdf8/K083718.pdf. Accessed 8 May 2013.

11. Sawada Y, Sone K. Treatment of scars and keloids with a cream containing silicone oil. Br J Plast Surg. 1990;43:683-8.

12. Sawada Y, Sone K. Hydration and occlusion treatment for hypertrophic scars and keloids. Br J Plast Surg. 1992;45:599-603.

13. Borgognoni L. Biological effects of silicone gel sheeting. Wound Repair Regen. 2002;10:118-21.
14. Reish RG, Eriksson E. Scars: a review of emerging and currently available therapies. Plast Reconstr Surg. 2008;122:1068-78.

15. Har-Shai Y, Lindenbaum E, Tendler M, GamlielLazarovich A, Feitelberg L, Hirshowitz B. Negatively charged static electricity stimulation as a possible mechanism for enhancing the involution of hypertrophic and keloid scars. Isr Med Assoc J. 1999;1:203-5.

16. Mustoe TA, Cooter RD, Gold MH, et al. International clinical recommendations on scar management. Plast Reconstr Surg. 2002;110:560-71.

17. Lyle WG. Silicone gel sheeting. Plast Reconstr Surg. 2001;107:272-5.

18. Kelo-cote: Patient information leaflet. http://www. kelo-cote.ca/Resources/Kelo-cote-Patient-BrochureFINAL-Jan2011.pdf. Accessed 22 August 2013.

19. Niessen FB, Spauwen PH, Schalkwijk J, Kon M. On the nature of hypertrophic scars and keloids: a review. Plast Reconstr Surg. 1999;104:1435-58.

20. Zouboulis CC, Blume U, Buttner P, Orfanos CE. Outcomes of cryosurgery in keloids and hypertrophic scars. A prospective consecutive trial of case series. Arch Dermatol. 1993;129:1146-51.

21. Hirshowitz B, Lerner D, Moscona AR. Treatment of keloid scars by combined cryosurgery and intralesional corticosteroids. Aesthetic Plast Surg. 1982;6:153-8.

22. Li-Tsang CW, Lau JC, Choi J, Chan CC, Jianan L. A prospective randomized clinical trial to investigate the effect of silicone gel sheeting (Cica-Care) on post-traumatic hypertrophic scar among the Chinese population. Burns. 2006;32:678-83.

23. Carney SA, Cason CG, Gowar JP, et al. Cica-Care gel sheeting in the management of hypertrophic scarring. Burns. 1994;20:163-7.

24. Nikkonen MM, Pitkanen JM, Al-Qattan MM. Problems associated with the use of silicone gel sheeting for hypertrophic scars in the hot climate of Saudi Arabia. Burns. 2001;27:498-501.

25. Ahn ST, Monafo WW, Mustoe TA. Topical silicone gel for the prevention and treatment of hypertrophic scar. Arch Surg. 1991;126:499-504.

26. Spencer JM. Case series: evaluation of a liquid silicone gel on scar appearance following excisional surgerya pilot study. J Drugs Dermatol. 2010;9:856-8.

27. Sepehrmanesh M. Scar Management: observational study of 1522 patients using Kelo-cote ${ }^{\circledR}$ Silicone Gel. Komp Dermatologie. 2006;1:30-2. 
28. Musgrave MA, Umraw N, Fish JS, Gomez M, Cartotto RC. The effect of silicone gel sheets on perfusion of hypertrophic burn scars. J Burn Care Rehabil. 2002;23:208-14.
29. Foo CW, Tristani-Firouzi P. Topical modalities for treatment and prevention of postsurgical hypertrophic scars. Facial Plast Surg Clin North Am. 2011;3:551-7. 